\title{
ROLE OF MDCT-CORONARY ANGIOGRAPHY IN THE EVALUATION OF CORONARY ARTERY ANOMALIES AND INCIDENCE OF CORONARY ARTERY ANOMALIES IN A SUBSET OF SOUTH INDIAN POPULATION
}

\author{
Senthil Kumar Aiyappan¹, Vadanika V2, Bulabai Karpagam³, S. Vinayagam4, K. C. Saravanan 5 \\ ${ }^{1}$ Associate Professor, Department of Radiodiagnosis, SRM Medical College and Research Institute, Katttangulathur, Kanchipuram, \\ Tamilnadu. \\ 2Junior Resident, Department of Radiodiagnosis, SRM Medical College and Research Institute, Katttangulathur, Kanchipuram, \\ Tamilnadu. \\ ${ }^{3}$ Associate Professor, Department of Radiodiagnosis, SRM Medical College and Research Institute, Katttangulathur, Kanchipuram, \\ Tamilnadu. \\ ${ }^{4}$ Professor, Department of Radiodiagnosis, SRM Medical College and Research Institute, Katttangulathur, Kanchipuram, Tamilnadu. \\ ${ }_{5}^{5}$ Professor, Department of Radiodiagnosis, SRM Medical College and Research Institute, Katttangulathur, Kanchipuram, Tamilnadu.
}

\begin{abstract}
AIM: To determine the role of MDCT-Coronary angiography in the evaluation of coronary artery anomalies and to calculate the prevalence of coronary artery anomalies in a subset of south Indian population.

MATERIALS AND METHODS: This is a retrospective study. Data of 250 consecutive patients who underwent CT coronary angiography in our institution over a period of 2 years were collected and analysed. The studies are analysed for the presence of abnormal origin and course of the arteries. Presence of anomalies of intrinsic coronary arterial anatomy like myocardial bridging were also evaluated. Few of these patients also underwent catheter coronary angiography and those findings were also included for analysis.
\end{abstract}

RESULTS: Out of 250 patients, 7 patients had anomalies of origin and course of coronary arteries, 9 patients had myocardial bridging. Of these 16 patients, 10 patients underwent catheter coronary angiography which gave less information than CTcoronary angiography.

CONCLUSION: The incidence of coronary artery anomalies in a subset of south Indian population was 6.4\% and MDCT-Coronary angiography better evaluated these anomalies than catheter coronary angiography.

KEYWORDS: Coronary Anomalies; MDCT-Coronary Angiography; Catheter Coronary Angiography; Myocardial Bridging.

HOW TO CITE THIS ARTICLE: Senthil Kumar Aiyappan, Vadanika V, Bulabai Karpagam, S. Vinayagam, K. C. Saravanan. "Role of MDCT-Coronary Angiography in the Evaluation of Coronary Artery Anomalies and Incidence of Coronary Artery Anomalies in a Subset of South Indian Population". Journal of Evolution of Medical and Dental Sciences 2015; Vol. 4, Issue 90, November 09; Page: 15561-15565, DOI: 10.14260/jemds/2015/2232.

INTRODUCTION: Congenital coronary artery anomalies are rare conditions which can be clinically silent. For several decades, diagnosis of coronary artery anomalies has been made with conventional angiography. However, this imaging technique has limitations due to its projectional and invasive nature.(1) Multi- detector computed tomography (MDCT) allows accurate and noninvasive depiction of coronary artery anomalies of origin, course, and termination. Multi- detector row CT is superior to conventional angiography in delineating the ostial origin and proximal path of an anomalous coronary.(1-3) Understanding the computed tomographic findings of various coronary artery anomalies is important for treatment planning and establishment of accurate diagnosis. In this retrospective study we try to evaluate the role of MDCT coronary angiography for diagnosis of coronary artery anomalies and to calculate the prevalence of coronary artery anomalies in a subset of south Indian population.

Financial or Other, Competing Interest: None. Submission 20-10-2015, Peer Review 21-10-2015,

Acceptance 29-10-2015, Published 09-11-2015.

Corresponding Author:

Dr. Senthil Kumar Aiyappan,

\#1880, $4^{\text {th }}$ Street, Vasantham Colony,

Annanagar West, Chennai-600040.

E-mail: senthilkumarpgi@yahoo.co.in

DOI:10.14260/jemds/2015/2232.
MATERIALS AND METHODS: This is a retrospective study conducted after getting approval from institutional ethics committee. Data of 250 consecutive patients who underwent CT coronary angiography in our institution, SRM medical college and research institute, Kancheepuram district, Tamilnadu, Chennai in a period of 2 years i.e from June 2013 to June 2015 were collected. The indications for CT coronary angiography and the findings were noted. The age of the patient and the risk factors for coronary artery disease were also noted. Patients with contraindications for CT and CT Coronary angiography like patients with renal failure and patients with arrhythmias were not included in the study.

All the CT-coronary angiography studies were done on 128- slice CT scanner, GE Company. The studies were analysed for the presence of abnormal origin and course of the coronary arteries. The arteries were analysed for anomalous aortic origin, anomalous aortic origin with anomalous proximal course and anomalous origin from the pulmonary artery. Other anomalies like presence of myocardial bridging and anomalous termination of coronary arteries were also evaluated.

Few of these patients also underwent catheter coronary angiography and the findings of those were also analysed. Catheter angiography was done in allura centron PHILIPS digital substraction angiography machine. The findings of CT coronary angiography was correlated with the findings of catheter angiography in patients who underwent both. 
The total number of cases with coronary artery anomalies were calculated and the prevalence was derived. Table 4 Shows the distribution of types of cases among coronary artery anomalies. Of the total 7 cases with coronary artery anomalies of origin and course, 2 patients had origin of the circumflex artery from the right coronary sinus, 2 patients had separate origin of the left anterior descending artery and circumflex artery from the left coronary sinus, one patient had left coronary artery originating from right sinus of valsalva and one patient had left coronary artery originating from pulmonary artery (ALCAPA) and one patient had congenitally absent left circumflex artery.

Nine cases of myocardial bridging were encountered which was diagnosed only using CT Coronary angiography. Hence the most common coronary artery anomaly in our study was myocardial bridging which is a type of anomaly of intrinsic coronary arterial anatomy. There were no cases of anomalous termination of coronary arteries. Of these 16 cases, 10 patients underwent catheter coronary angiography which gave relatively less information about the course and origin of the coronary arteries when compared to multidetector CT coronary angiography.

DISCUSSION: Anomalous coronary arteries are found in 0.1 $1.3 \%$ of the population. ${ }^{(4)}$ However with the increasing use of MDCT angiography, the prevalence of coronary artery anomalies have increased. In our study the prevalence was about $6.4 \%$. In a recent study by Ghadri et al. the prevalence of coronary artery anomalies was $7.9 \%$. Such anomalous branches may be associated with congenital heart disease or occur in isolation. Three broad groups in classifying anomalous coronary arteries include 1 . Anomalies of origin and course 2. Anomalies of intrinsic coronary arterial anatomy 3. Anomalies of coronary termination. $(4,5)$ We did not encounter any case of anomaly of coronary artery termination.

Anomalous origin of coronary artery can be categorized into three groups which include, anomalous aortic origin, anomalous aortic origin with anomalous proximal course, and anomalous origin from the pulmonary artery.(1-3) The most common congenital anomaly in anomalies of origin and course is separate origin of the left anterior descending artery and circumflex artery from the left coronary sinus and second most common is the Origin of the circumflex artery from the right coronary sinus.(6) The most common anomaly of intrinsic coronary arterial anatomy is myocardial bridging.

In our study the most common coronary artery anomaly was myocardial bridging contributing to $56 \%$ of cases of anomalous coronary arteries. Myocardial bridging is a congenital anomaly in which a segment of a coronary artery takes a "tunneled" intramuscular course under a "bridge" of overlying myocardium. This causes vessel compression in systole, resulting in hemodynamic changes that may be associated with angina, myocardial ischemia and even sudden cardiac death.(7)

Congenitally absent left circumflex artery is an extremely rare anomaly of coronary arteries with only a small number of cases having been reported, but its incidence is increasing due to the wide use of MDCT Coronary angiography.(8,9) (Fig. 1). In our study, we encountered one case of congenitally absent left circumflex artery. Anomalous course or origin of left circumflex artery can be easily diagnosed using MDCT angiography. In most cases, the anomalous circumflex branch arise from the right sinus of
Valsalva or alternatively, branches of from the right coronary artery itself. Invariably, the circumflex artery then follows a retrocardiac or retroaortic course behind the aorta and ventral to the left atrium which is considered benign (Fig. 2) and do not necessitate intervention.(8)

Anomalies involving the right coronary artery or the left main coronary artery also can occur. Some variants, such as anomalous right coronary artery following an interarterial course between the aorta and the right ventricular outflow tract are considered malignant variant and are associated with myocardial ischemia with increased morbidity and mortality, and are often treated with surgical reimplantation or coronary artery revascularization.(6) The incidence of coronary artery arising from wrong sinus is $1.07 \%$ and the incidence of origin of left coronary artery from right sinus of valsalva is even rarer of $0.15 \%$.

There are four variants of anomalous left coronary artery arising from right sinus of valsalva namely posterior or retroaortic course (Fig. 2), interarterial or preaortic course, anterior or prepulmonic course and septal or subpulmonic course. $(9,10)$ The left main coronary artery or left anterior descending artery arising from the right coronary sinus of Valsalva and right coronary artery originating from the left coronary sinus of Valsalva may be associated with sudden cardiac death, hence deserve special attention.(6)

Anomalous origin of the left coronary artery from the pulmonary trunk (ALCAPA), also known as Garland-BlandWhite syndrome, is an extremely rare but potentially fatal congenital cardiovascular anomaly with an incidence of 1 in 300,000 live births.(11,12) Most of them are diagnosed within first month of life and present with cardiomyopathy and congestive heart failure. Nearly 90 per cent of untreated patients die within one year, however, a few patients can survive into adulthood with adequate collateral blood supply to the left coronary circulation through dominant right coronary artery (Fig. 3).

Some reports have found its association with tetralogy of Fallot, complete atrioventricular septal defect, and aortopulmonary window, which arises secondary to failure of septation in the aorticopulmonary trunk. Surgery is the definitive treatment of choice. We encountered one case of ALCAPA in an adult male. Multidetector Coronary CT (MDCT) angiography can demonstrate both the primary and secondary features of coronary artery anomaly in 3dimensional projection thereby helping the surgeon.

MDCT depict these anomalies with high accuracy and provides high-resolution 3D data sets that allow precise definition of 3D spatial relations of the anomalies. (3,4) MDCTCoronary angiography is better than conventional angiography in delineating the ostial origin and proximal path of an anomalous coronary. Increased use of MDCT in cardiac imaging highlights the value of recognizing such anomalies on cross-sectional, multiplanar, and volumerendered reconstructions.

CONCLUSION: In this study we have tried to evaluate the role of noninvasive multidetector CT angiography in diagnosing coronary artery anomalies and found that, it is better than conventional catheter angiography in depicting the ostial origin and proximal path of an anomalous artery. The prevalence of coronary artery anomalies in a subset of south Indian population in our study was very rare and found to be $6.4 \%$, although this cannot be applied to general population. 


\section{REFERENCES:}

1. Joon-Won Kang, Joon Beom Seo, Eun Jin Chae, Yu M i Jang, Kyung-Hyun Do, Jin Seong Lee, Jae-Woo Song, TaeHwan Lim. Coronary Artery Anomalies: Classification and Electrocardiogram-Gated Multidetector Computed Tomographic Findings. Seminars in Ultrasound, CT and MRI.

2008; 29: 182-194.

2. Kim, S. Y, Seo, J. B., Do, K. H. et al, Coronary artery anomalies: classification and ECG-gated multi-detector row CT findings with angiographic correlation. Radiographics. 2006; 26:317-334.

3. Dodd J. D, Ferencik M, Liberthson R. R, Cury R. C, Hoffmann U, Brady T. J, Abbara S. Congenital anomalies of coronary artery origin in adults: 64-MDCT appearance. AJR Am J Roentgenol. 2007 Feb; 188(2):W138-46.

4. Ghadri J. R, Kazakauskaite E, Braunschweig S, Burger I. A, Frank M, Fiechter M,Gebhard C, Fuchs T. A, Templin C, Gaemperli O, Lüscher TF, Schmied C, Kaufmann P. A. Congenital coronary anomalies detected by coronary computed tomography compared to invasive coronary angiography. BMC Cardiovasc Disord. 2014 Jul 8; 14:81.

5. Angelini P. Novel imaging of coronary artery anomalies to assess their prevalence, the causes of clinical symptoms, and the risk of sudden cardiac death. Circ Cardiovasc Imaging. 2014 Jul; 7(4):747-54.
6. Yildiz A1, Okcun B, Peker T, Arslan C, Olcay A, Bulent Vatan M. Prevalence of coronary artery anomalies in 12,457 adult patients who underwent coronary angiography. Clin Cardiol. 2010 Dec; 33(12):E60-4.

7. Lee M. S, Chen C. H. Myocardial Bridging: An Up-to-Date Review. J Invasive Cardiol. 2015 May 15.

8. GuoJ, Xu M. Congenital absence of the left circumflex artery associated with inferior myocardial infarction. Intern Med. 2012; 51(1):71-4.

9. Hongsakul K, Suwannanon. R Congenital absence of left circumflex artery detected by computed tomography coronary angiography: a casereport. Case Rep Vasc Med. 2012; 2012:204657.

10. Ramos A, Brizida L, Carvaiho R, Matias F, Mourao L Acute myocardial infarction associated with anomalous origin of coronary arteries (a rare case of origin of the left coronary artery from the ostium of the right coronary artery). Rev Port Cardiol. 2010 Jul-Aug; 29(7-8):1245-51.

11. Haghighi ZO, Poorzand H, Bassiri HA. Presentation of anomalous origin of the left coronary artery from the pulmonary artery with left sided coronary ostium in an adult patient.

Iranian Cardiovascular Res J 2009; 3: 109-15.

12. Tseng KF Anomalous origin of left coronary artery from the pulmonary trunk in a mildly symptomatic adult female. Case Rep Surg. 2013; 2013:840741.

RESULTS: The age and sex distribution of the patients were given below in Table 1 and 2.

\begin{tabular}{|c|c|}
\hline AGE & NUMBERS \\
\hline $10-30$ & 1 \\
\hline $30-40$ & 23 \\
\hline $40-50$ & 48 \\
\hline $50-60$ & 62 \\
\hline $60-70$ & 83 \\
\hline $70-80$ & 33 \\
\hline \multicolumn{2}{|c|}{ Table 1: Age Distribution of Study Group } \\
\hline \multicolumn{2}{|c|}{}
\end{tabular}

The maximum study population were between 40 to 70 years.

\begin{tabular}{|c|c|c|}
\hline Sex & Frequency & Percent \\
\hline F & 98 & 39.2 \\
\hline M & 152 & 60.8 \\
\hline Total & $\mathbf{2 5 0}$ & $\mathbf{1 0 0}$ \\
\hline \multicolumn{2}{|c|}{ Table 2: Sex Distribution } \\
\hline
\end{tabular}

Males contributed to more than half of patients.

\begin{tabular}{|c|c|}
\hline Types of cases & Number \\
\hline Coronary artery disease & 157 \\
\hline $\begin{array}{l}\text { Abnormalities of origin and course of } \\
\text { coronary arteries }\end{array}$ & 7 \\
\hline Myocardial bridging & 9 \\
\hline Post coronary artery bypass surgery & 11 \\
\hline Status post coronary artery stenting & 6 \\
\hline Status post coronary artery stenting & 12 \\
\hline Normal CT Coronary angiography & 48 \\
\hline Total & 250 \\
\hline \multicolumn{2}{|c|}{ Table 3: Distribution of Types of Cases } \\
\hline
\end{tabular}

Table 3 shows distribution of types of cases and the maximum number of cases were of coronary artery diseases contributing to $63 \%$ of cases. The coronary artery anomalies which included abnormalities of origin and course of coronary arteries and myocardial bridging contributed to $6.4 \%$ of total number of cases. 


\begin{tabular}{|c|c|}
\hline Types of cases & Number \\
\hline Origin of the circumflex artery from the right coronary sinus & 2 \\
\hline $\begin{array}{c}\text { Separate origin of the left anterior descending artery and circumflex artery } \\
\text { from the left coronary sinus }\end{array}$ & 2 \\
\hline Anomalous left coronary artery arising from right sinus of valsalva & 1 \\
\hline Anomalous left coronary artery originating from pulmonary artery (ALCAPA) & 1 \\
\hline Congenitally absent left circumflex artery & 1 \\
\hline Myocardial bridging (Anomaly of intrinsic coronary arterial anatomy) & 9 \\
\hline TOTAL & $\mathbf{1 6}$ \\
\hline \multicolumn{2}{|c|}{ Table 4: Distribution of Cases of Coronary Artery Anomalies } \\
\hline
\end{tabular}

Figure 1A and B: 40-year-male with chest pain for evaluation detected to have absent left circumflex artery: 3-D volume rendered CT coronary angiography images showing absent left circumflex artery.

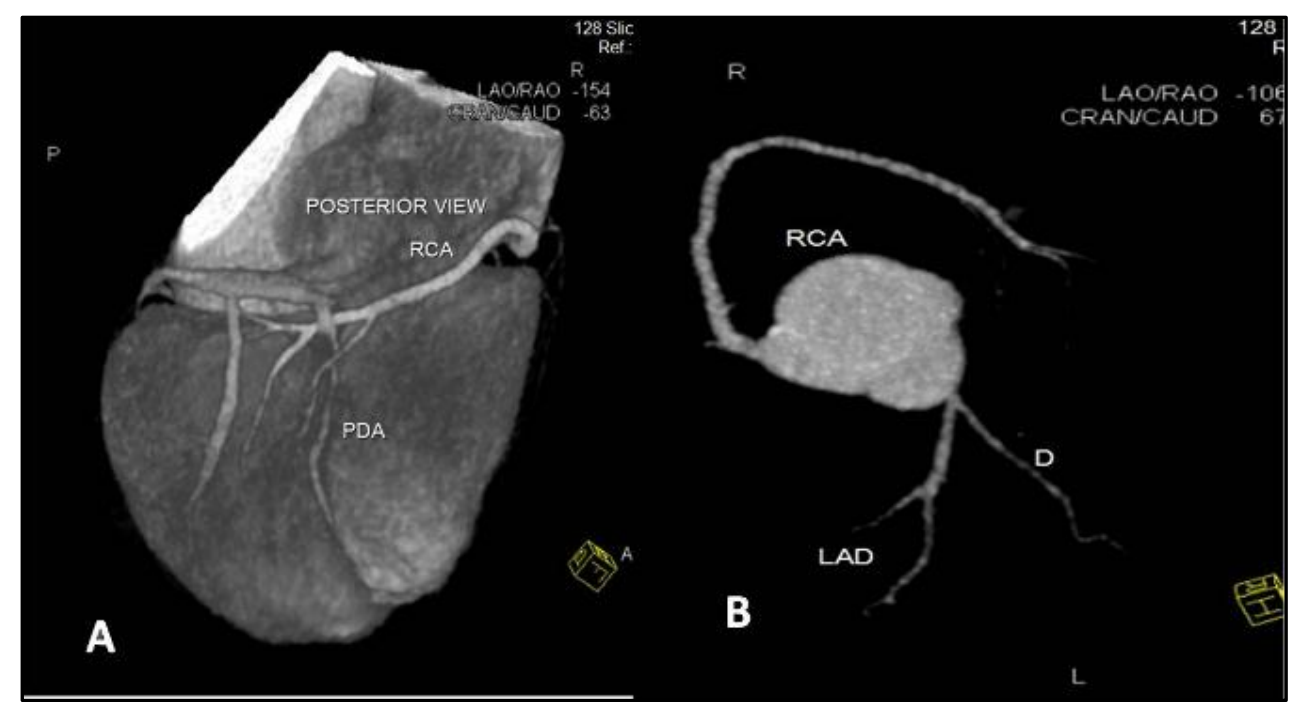

Fig. $1 A \& B$

Figure 2A and B: 54-year-old asymptomatic male with benign retroaortic course of left circumflex artery arising from right coronary ostium : 3-D volume rendered CT coronary angiography images showing benign retroaortic course of left circumflex artery arising from right coronary ostium (White arrows).

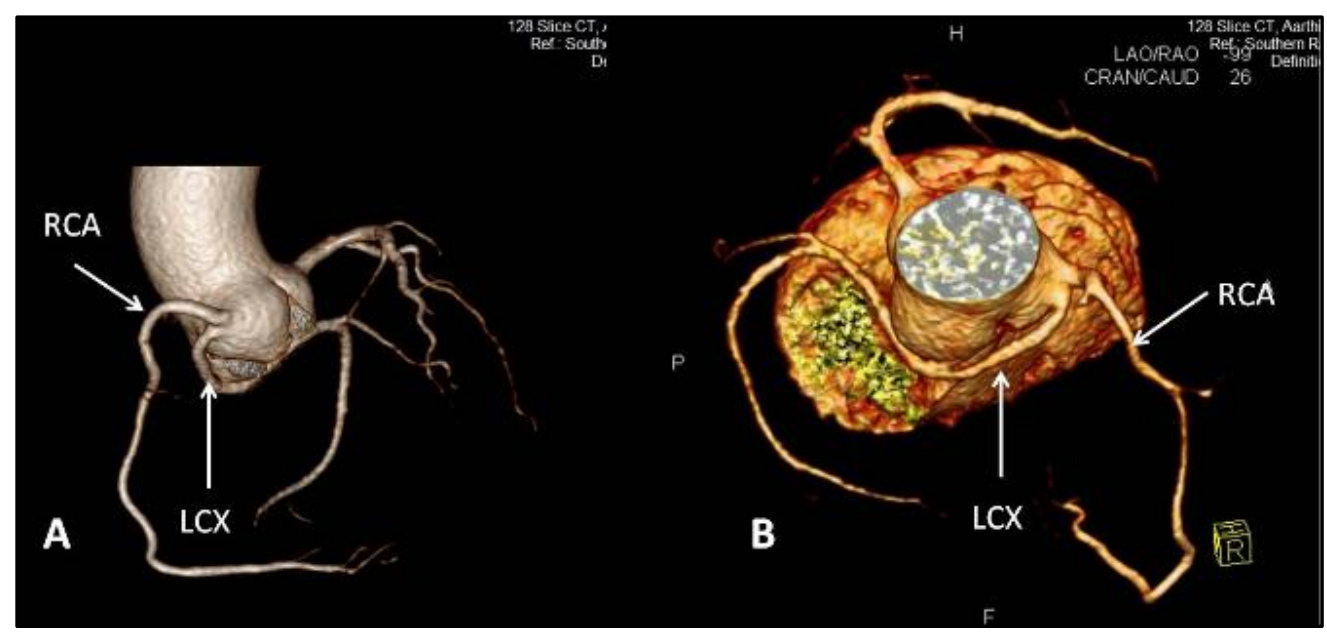

Fig. $2 A \& B$ 


\section{Jemds.com}

Original Article

Figure 3A and B: 58-year-old male with anginal chest pain for evaluation detected to have ALCAPA: A- Axial CT coronary angiography image showing origin of left coronary artery from main pulmonary artery (White arrow) and B- Coronal 3-D MIP CT coronary angiography image showing left coronary artery arising from pulmonary artery (White arrow) with dilated tortuous right coronary artery and its collateral branches (Black arrows).

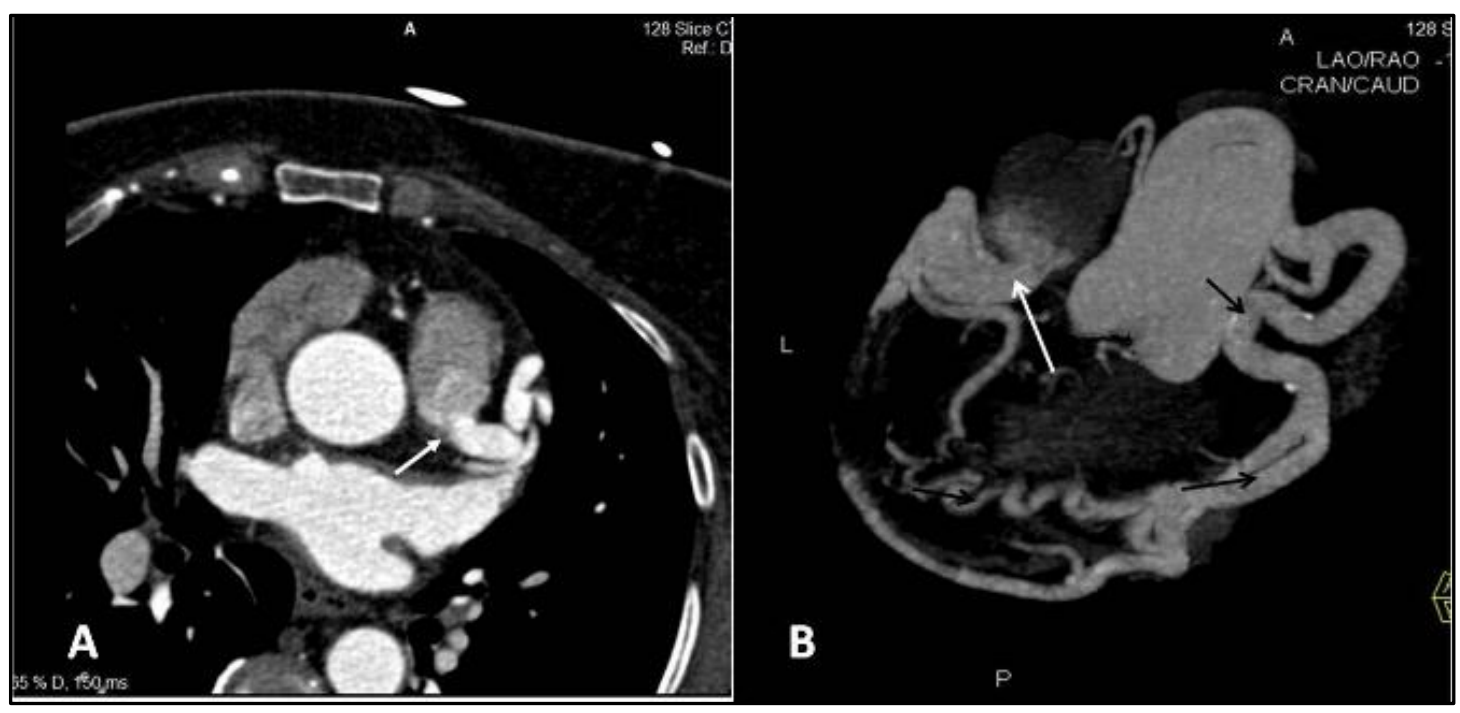

Figure $3 A$ and $B$ : 